\title{
Şuhut (Afyonkarahisar) Batısı Su Kaynaklarının Hidrojeoloji ve Hidrojeokimyasal İncelemesi
}

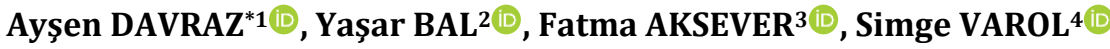 \\ 1,2,3Süleyman Demirel Üniversitesi, Mühendislik Fakültesi, Jeoloji Mühendisliği Bölümü, 32260, Isparta, Türkiye \\ ${ }^{4}$ Süleyman Demirel Üniversitesi, Su Enstitüsü, 32260, Isparta, Türkiye
}

(Alınış / Received: 03.04.2019, Kabul / Accepted: 21.05.2019, Online Yayınlanma / Published Online: 30.08.2019)

\section{Anahtar Kelimeler}

Su kaynağı, Hidrojeokimya, Hidrojeoloji, Şuhut

\begin{abstract}
Özet: Bu çalışmada, Şuhut (Afyonkarahisar) ilçesi batısında bulunan su kaynaklarının hidrojeokimyasal özellikleri incelenmiștir. Kaynak sularından Eylül2017 ve Nisan-2018 dönemlerinde yapılan analiz sonuçlarına göre $\mathrm{CaMgHCO}_{3}$, $\mathrm{CaNaSO}_{4}, \mathrm{CaNaHCO}_{3}$ ve $\mathrm{CaHCO}_{3}$ su tipleri tespit edilmiştir. Su kaynaklarının Eylül2017 ve Eylül-2018 arasında aylık periyodik debi ölçümleri yapılmıştır. Kaynakların yıllık baz akım değerleri $311.04-4302.72 \mathrm{~m}^{3} / \mathrm{yll}$ ve ortalama debi değerleri 0.01-1.81 l/s arasında değiş̧mektedir. Kaynak sularının genel olarak fiziksel özellikleri ve anyon-katyon içerikleri açısından içme suyu sınır değerlerini

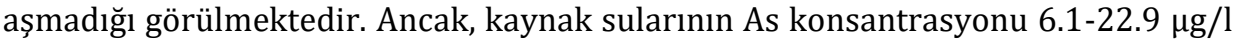
arasında değişmektedir. Kumalar kaynağı ve Deveyatağı kaynağı dışındaki bütün kaynak sularında kaya-su etkileșimine bağlı olarak As artışı tespit edilmiștir. Kayabelen'de bulunan Dedecik kaynağının $\mathrm{Fe}, \mathrm{Mn}$ ve Ni içerikleri de içme suyu standart değerlerinin üzerindedir. Kaynak sularındaki ağır metal artışları genelde volkanik kayaçlarla ilişkili olarak jeojenik kökenlidir. Kumalar kaynağı içmesuyu olarak kullanıma en uygun kaynaktır. Bölgede kaynak sularının sulama suyu olarak kullanıma uygun olduğu tespit edilmiștir.
\end{abstract}

\section{Hydrogeological and Hydrogeochemical Investigation of Water Springs in West of the Şuhut (Afyonkarahisar)}

\section{Keywords}

Water spring,

Hydrogeochemistry,

Hydrogeology,

Şuhut

\begin{abstract}
In this study, the hydrogeochemical properties of the water springs in the west of the district of Şuhut (Afyonkarahisar) were investigated. $\mathrm{CaMgHCO}_{3}$, $\mathrm{CaNaSO}_{4}, \mathrm{CaNaHCO}_{3}$ and $\mathrm{CaHCO}_{3}$ water types were identified in spring waters according to analysis results in in the September-2017 and April-2018. Monthly periodic flow rate measurements were made between September-2017 and September-2018 in the water springs. The annual base flow values and the average yields of the water springs are between 311.04-4302.72 $\mathrm{m}^{3} /$ year and 0.01-1.81 $\mathrm{l} / \mathrm{s}$, respectively. In the study area, it is observed that the waters do not exceed the limit values in terms of physical properties and anion-cation contents. However, the As concentration of the spring waters varies between 6.1-22.9 $\mu \mathrm{g} / \mathrm{l}$. As increase was determined due to rock-water interaction in all spring waters except for Kumalar spring. Fe, Mn and Ni contents of the Dedecik spring in Kayabelen are also above the drinking water standard values. Heavy metal increases in spring waters are generally geogenic origin in relation to volcanic rocks. Kumalar spring is the most suitable source for drinking water. It has been determined that the spring waters are suitable for irrigation water.
\end{abstract}

\section{Giriş}

Canlıların yaşamında en önemli ihtiyaç olan su, doğal bir kaynaktır. Toplumun sosyal ve ekonomik faaliyetlerinin devamlılığı için temiz ve devamlılığı sağlanmış su kaynaklarına ihtiyaç vardır. Ancak dünya üzerinde doğal süreçler ve insan faktöründen

*ilgili yazar: aysendavraz@sdu.edu.tr dolayı su kaynakları azalmaktadır. Özellikle, kentleşme, nüfus artışı, artan yaşam standartları ve farklı insan faaliyetleri ile oluşan kirlilikler su kaynakları üzerindeki baskıları giderek artırmaktadır. Bunlara iklim değișimi ve doğal koşullardaki değişiklikler de eklendiğinde mevcut su kaynaklarının korunması gittikçe zorlaşmaktadır. Su 
kaynaklarının optimum kullanımının öneminin anlaşıldığı günümüzde ülkemizin başlıca kullanılabilir su kaynakları olan yeraltısularından en iyi şekilde faydalanmak ve sürdürülebilirliğini sağlamak, sağlıklı hidrojeoloji çalışmaları ile mümkündür.

Yeraltısularından faydalanma doğal boşalan kaynak sularının kullanımı ve derin-sığ kuyular açılmasıyla elde edilen yeraltısuyunun kullanımı şeklindedir. Doğal kaynak boşalımları ulaşılmasının kolay ve ekonomik olması nedeniyle yaygın olarak kullanılmaktadır. Ancak, bu kaynakların en uygun şekilde ve sürdürülebilirliğinin sağlanması için hidrojeolojik ve hidrojeokimyasal araştırmaların yapılması zorunludur. Su kaynaklarının kullanımın denetleyen parametrelerin başında suyun kalitesi yani fiziksel ve kimyasal özellikleri ile miktarı gelmektedir.

İnceleme alanı olarak Ege Bölgesi'nin İç Batı Anadolu bölümünde, Afyonkarahisar ilinin güneybatısında bulunan Şuhut ilçesinin batı kesimleri seçilmiştir (Şekil 1). İnceleme alanında çok sayıda kaynak suyu bulunmakta ve yöre halkı tarafından yaygın olarak kullanılmaktadır. Günümüzde mevcut su kaynaklarının sürdürülebilir kullanımı için, su kaynaklarının potansiyel ve kalite açısından izlenmesi, su kalitesini değiştiren olumsuz etkilerin önlenmesi veya en aza indirilmesi konularında çözüm üreten çalışmaların yürütülmesi zorunluluk haline gelmiştir. Bu çalışmanın amacı; Şuhut batısında kalan bölgede yeralan su kaynaklarının optimum ve sürdürülebilir kullanımının sağlanabilmesi için gerekli jeolojik, hidrojeolojik ve hidrojeokimyasal araştırmaların yapılmasıdır. Elde edilen verilerle su kaynak yönetimi açısından değerlendirmeler yapılmıştır.

\section{Materyal ve Metot}

İnceleme alanının kuzeyinde Afyonkarahisar İli, batısında Sandıklı ve Sinanpaşa İlçeleri, güney batısında Dinar İlçesi, güneyinde Karaadilli Ovası, doğusunda Çay İlçesi bulunmaktadır. Bu bölgede çok sayıda su kaynağı bulunmaktadır. Kaynak suları yöre halkı tarafından içme, kullanma, hayvan yetiştiriciliği ve sulama amaçları için kullanılmaktadır. $\mathrm{Bu}$ kaynakların çoğu kontrolsüz ve korunmasız olarak akmakta ve yüzey suyuna boşalmaktadır. Sözkonusu kaynakların debileri, kimyasal ve fiziksel özellikleri ile miktarı konularında herhangi bir araștırma bulunmamaktadır.
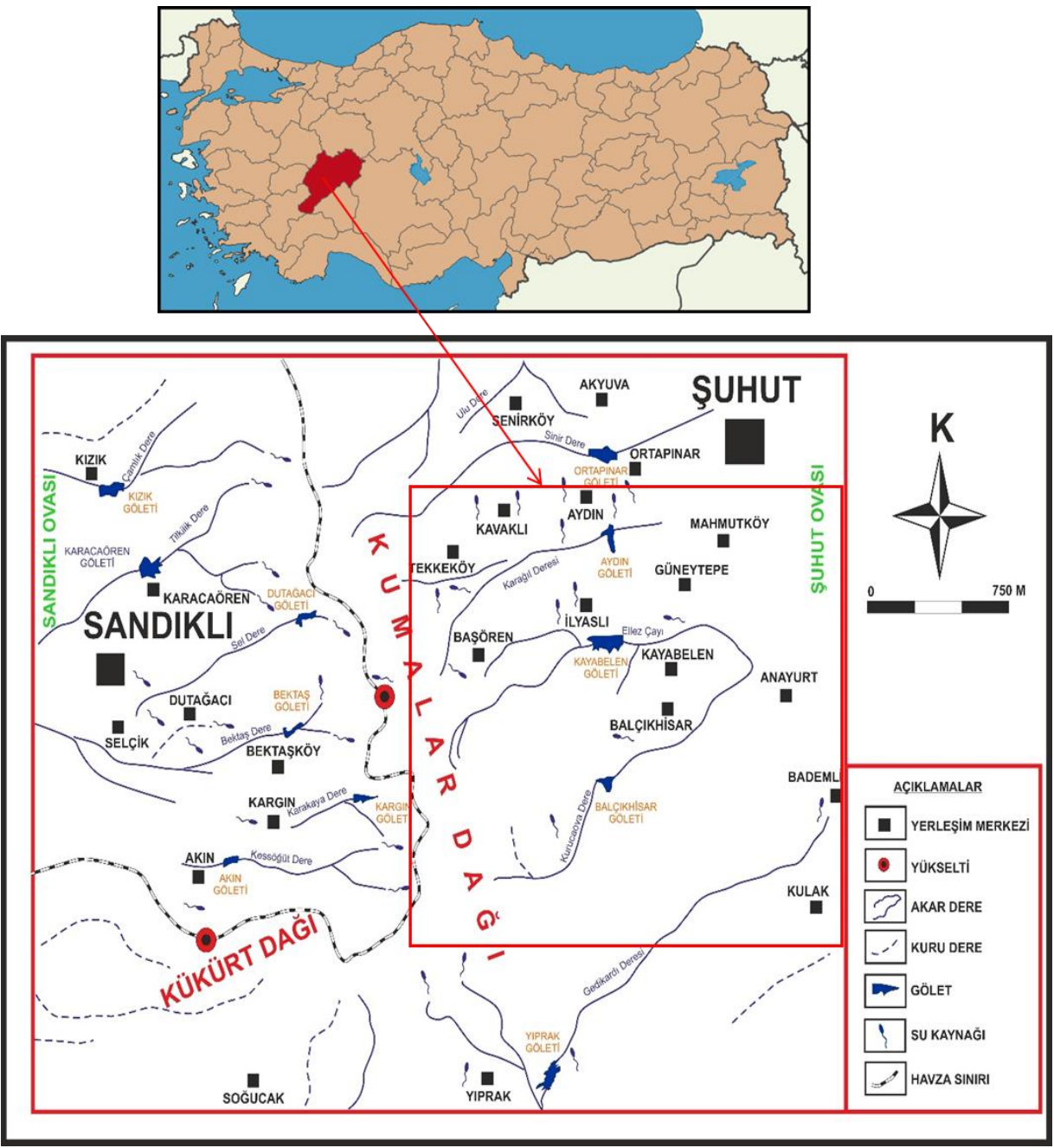

Şekil 1. İnceleme alanının yer bulduru haritası 
İnceleme alanında bulunan su kaynakları arazi çalışmalarıyla tespit edilmiştir. Belirlenen su kaynaklarının aylık debi ölçümleri yapılmış ve baz akımları hesaplanmıștır.

Su kimyası ve kirliliğe yönelik çalışmalar kapsamında bölgenin tamamını temsil edecek şekilde su kaynaklarından kurak (Eylül-2017) ve yağışlı (Nisan2018) dönemlere ait su örnekleri alınmıştır. Suların fiziksel parametreleri olan hidrojen iyon konsantrasyonu $(\mathrm{pH})$, sicaklı $\left(\mathrm{T}^{\circ} \mathrm{C}\right)$ ve özgül elektriksel iletkenlik (EC- $\mu \mathrm{S} / \mathrm{cm}$ ) gibi parametrelerin arazide ölçümlerinde Hach Lange marka HQ40D model portatif çoklu ölçüm cihazı kullanılmıştır. Majör element $\left(\mathrm{Na}^{+}, \mathrm{K}^{+}, \mathrm{Ca}^{+2}, \mathrm{Mg}^{+2}, \mathrm{Cl}^{-}, \mathrm{SO}^{-2}, \mathrm{HCO}_{3}{ }^{-}\right.$, $\left.\mathrm{CO}_{3}^{-2}\right)$ ve nitrat $\left(\mathrm{NO}_{3}^{-}\right)$, nitrit $\left(\mathrm{NO}_{2}^{-}\right)$amonyak $\left(\mathrm{NH}_{4}\right)$, flor (F) ve fosfat $\left(\mathrm{PO}_{4}^{-3}\right)$ analizleri Hacettepe Üniversitesi $\mathrm{Su}$ Kimyası ve Çevresel Trityum laboratuvarında yaptırılmıştır. Ağır metal analizleri ise ( $\mathrm{Mn}, \mathrm{Cu}, \mathrm{Zn}, \mathrm{Pb}, \mathrm{Ni}, \mathrm{Cd}, \mathrm{B}, \mathrm{As}, \mathrm{Fe}, \mathrm{Cr}$ vb.) Canada Bureau Veritas Mineral Laboratories (Acme Analitik Laboratuvarl), Inductively Coupled Plasma - Mass Spectrometer (ICP-MS) cihazı ile yapılmıştır. Elde edilen sonuçlar farklı diyagramlar ve haritalar üzerinde yorumlanarak çeşitli kullanım alanları açısından uygunluğu değerlendirilmiştir. Su kaynaklarından alınan örneklerde çevresel izotop içerik (Oksijen 18 - ${ }^{18} \mathrm{O}$, Döteryum - ${ }^{2} \mathrm{H}$, Trityum - ${ }^{3} \mathrm{H}$ ) analizleri DSİ Genel Müdürlüğü Teknik Araştırma ve Kalite Kontrol (TAKK) Daire Başkanlığı İzotop Laboratuvarı'nda yapılmıştır.

\subsection{Kaynak hidrografi analizi}

Kaynaklardan yararlanılması düşünüldüğünde kaynağın yağışlara bağlı olmaksızın boşalttığı su miktarının bilinmesi gereklidir. Bu nedenle kaynağın baz akımlarının hesabı büyük önem taşımaktadır.

Baz akım; Yağışların etkisi olmaksızın kaynağın kendi rezervuarından boşalttığı su miktarıdır. Kaynağın baz akımının hesaplanmasında kullanılan yöntemlerden birisi kaynak hidrografı analizidir.

Hidrograf analizinde, kaynağın birkaç yıl aylık düzenli debi ölçümleri alınır. Bu ölçümler, zaman(ay) yatay eksende, debi (l/s) düşey eksende olmak üzere debi-zaman grafiğine noktalar halinde yerleştirilir. Grafikte en düşük noktalar dikkate alınarak "baz akım eğrisi” çizilir. Her yıl için baz akım eğrisinin altındaki alanlar ayrı ayrı hesaplanır. Birim alana düşen su miktarının belirlenmesi amacıyla, çizilen grafiğin ölçeğinden yararlanarak her yıl için ayrı ayrı ortalama akış debisi hesaplanır.

\section{Bulgular}

\subsection{Jeoloji ve hidrojeoloji}

İnceleme alanında Anamas-Akseki Otoktonu, Beyşehir-Hoyran-Hadim Napları ve örtü kayalarına ait birimler bulunmaktadır (Şekil 2). Bölgede Anamas-Akseki Otoktonu Homa Akdağ Birimi'ne ait Hüseyinliçeşme, Sarıdere, Kocaçal, Beleceğez, Kocadere ve İlyaslı formasyonları ile temsil edilmektedir [1, 2]. Beyşehir-Hoyran-Hadim Napları ise Kükürtdağ grubuna ait Göçen, Kayrakdağ, Sütlaçtepe ve Afyonluk formasyonları ile Sazak grubuna ait Koyuntepe, Bakırdağ ve Ortatepe formasyonlarını içermektedir. Örtü kayaçları olarak Akçaköy formasyonu Şuhut Grubuna ait Karataş ve Kumalar formasyonları ile Volkanit üyesi, Kuzbaşı üyesi, alüvyon ve yamaç molozu birimleri yüzeylemektedir.

Bölgedeki jeolojik birimler hidrojeolojik özelliklerine göre değerlendirilerek hidrojeoloji haritası hazırlanmıștır (Şekil 3). İnceleme alanında geniş alanlarda yüzeyleyen Kuvaterner alüvyon, yamaç molozu, birikinti konileri ve alüvyon yelpazesi Taneli akifer olarak tanımlanmıştır. $\mathrm{Bu}$ gözenekli yapı birimin iyi bir akifer olmasını sağlamaktadır. İnceleme alanı ve çevresinde alüvyon birimde açılmış çok sayıda sondaj kuyusu yer almaktadır.

İnceleme alanında kireçtaşlarından oluşan karbonat kayaçlar karstik akifer olarak tanımlanmıştır. Bu formasyonlar; Kocaçal, Sarıdere, Bakırdağ, Koyuntepe, Ortatepe, Afyonluk, Sütlaçtepe ve Kayrakdağ formasyonlarıdır. İnceleme alanı ve çevresinde bu birimlerden kaynak boşalımları bulunmaktadir.

Çakıltaşı, kumtaşı, silttaşı ardalanmasından oluşan İlyaslı formasyonu, Yastık lav, kumtaşı, kireçtaşı litolojilerinden oluşan Belceğez ve kumtaşı, kiltaşı, silttaşı, kireçtaşı ardalanmasından oluşan Kocadere formasyonları [3]. benzer hidrojeolojik özellik taşımaları nedeniyle Akitard Ortam-1 olarak tanımlanmıştır [4].

İnceleme alanında geniş alanlarda yüzeyleyen, volkanik kökenli kayaçlar ile kırıntılı kireçtaşlarından meydana gelen Kumalar formasyonu ile küçük alanlarda gözlenen Göçen formasyonu ve Kumalar formasyonunun volkanit üyesi Akitard Ortam-2 olarak tanımlanmıştır. Birimler içerisinde bulunan traki-andezitler ve bazaltlar bol kırık ve çatlaklı yapılarının yanı sıra gözenekli yapıya sahip olmaları nedeniyle geçirimli özelliğe sahiptir [5].

Benzer litolojik birimlerden oluşan Karataş formasyonu ve Hüseyinliçeşme formaşyonu ile Kumalar formasyonunun Kuzbaşı üyesi Akifüj ortam olarak tanımlanmıştır. Kiltaşı, silttaşı, marn ve şeylerden oluşan birimler yeraltısuyu içermemektedir. İnceleme alanında küçük alanlarda gözlenen formasyonlar içerisindeki litolojik birimlerin akifer olabilme kapasitelerinin olmaması nedeniyle geçirimsiz birim olarak değerlendirilmiştir. 


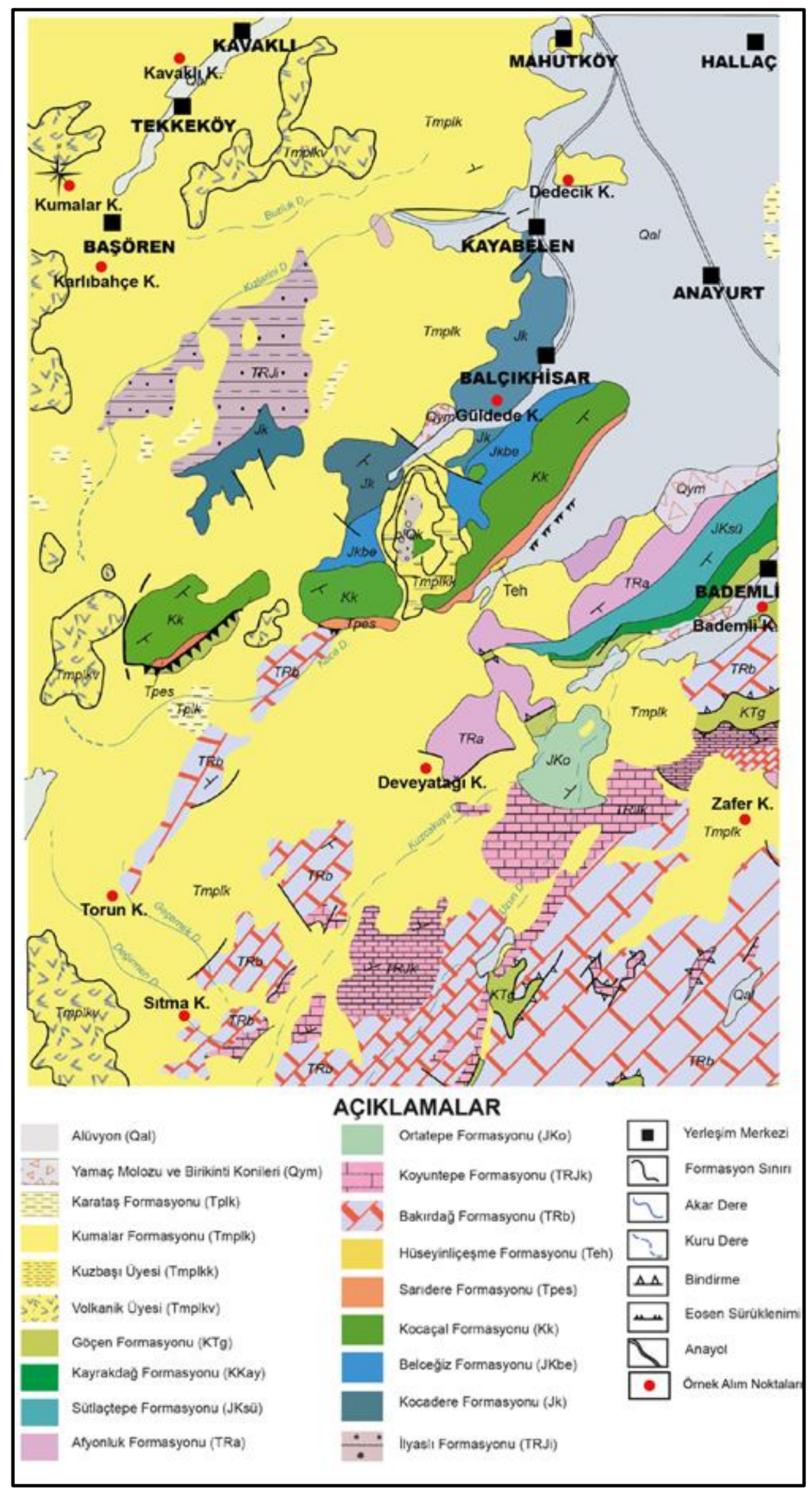

Şekil 2. İnceleme alanının jeoloji haritası $[1,2,4]$ 


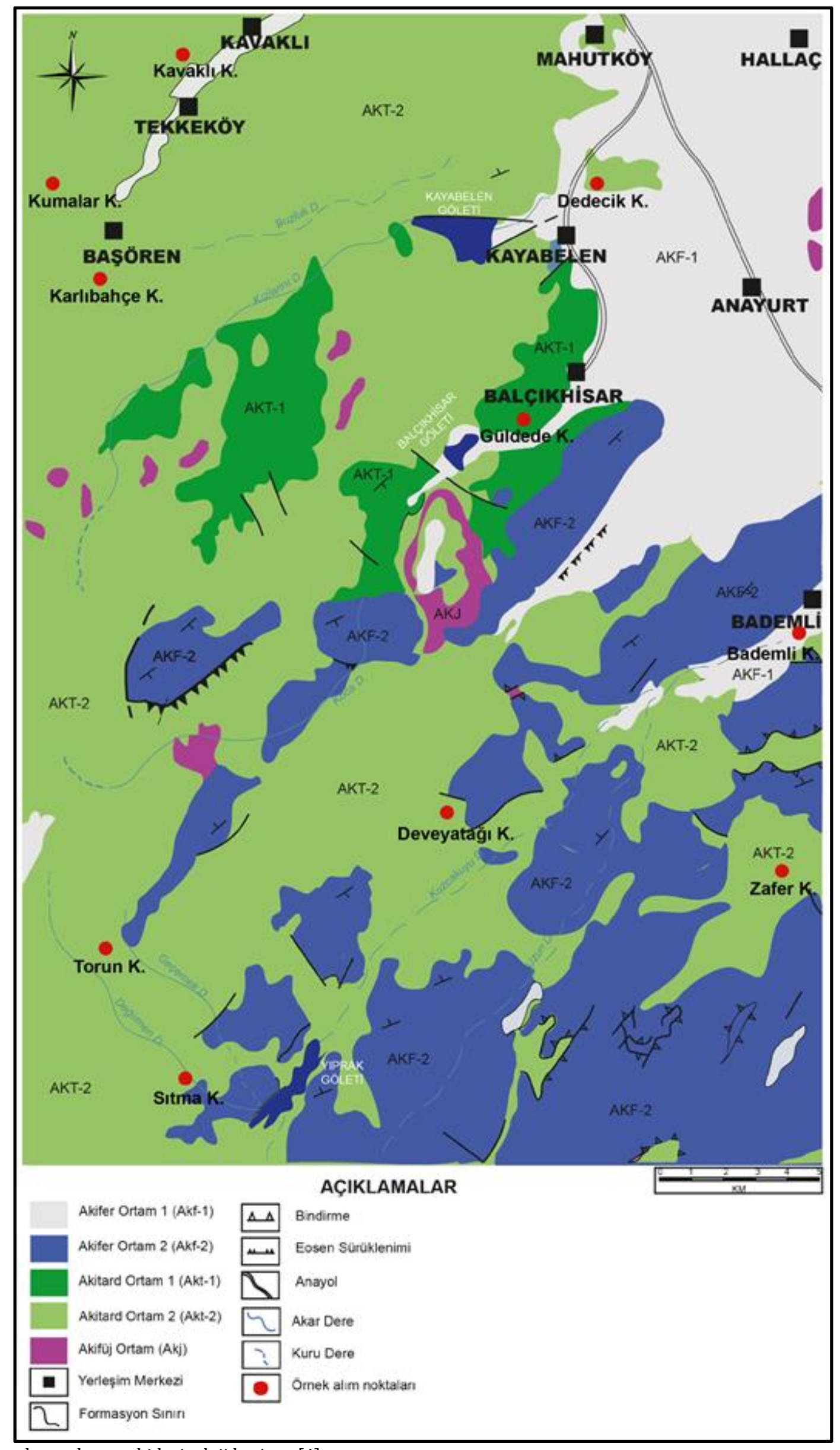

Şekil 3. İnceleme alanının hidrojeoloji haritası [4] 


\subsection{Hidrojeokimya}

Eylül-2017 ve Nisan-2018 döneminde alınan su örneklerinin kimyasal analiz ve yerinde ölçüm sonuçları Tablo 1'de verilmiştir. İnceleme alanında yeraltısuları sertliği Eylül-2017 döneminde 3.1917.35 $\mathrm{Fr}^{0}$, Nisan-2018 döneminde ise 2.63-24.17 $\mathrm{Fr}^{0}$ değerleri arasındadır.
Kaynak sularının majör element analiz sonuçları Piper [5] diyagramı üzerinde gösterilmiştir (Şekil 4). Her iki dönemde de 3 ayrı su tipi tespit edilmiștir. Kumalar ve Karlıbahçe ve Deveyatağı kaynakları $\mathrm{CaMgHCO}_{3}$, Kavaklı ve Dedecik kaynakları CaNaSO Sitma, Torun, Güldede, Bademli ve Zafer kaynakları ise $\mathrm{CaHCO}_{3}{ }^{\prime}$ lı sular sınıfindadır.

Tablo 1. Kaynak sularının kimyasal analiz sonuçları (Eylül 2017- Nisan 2018) [4]

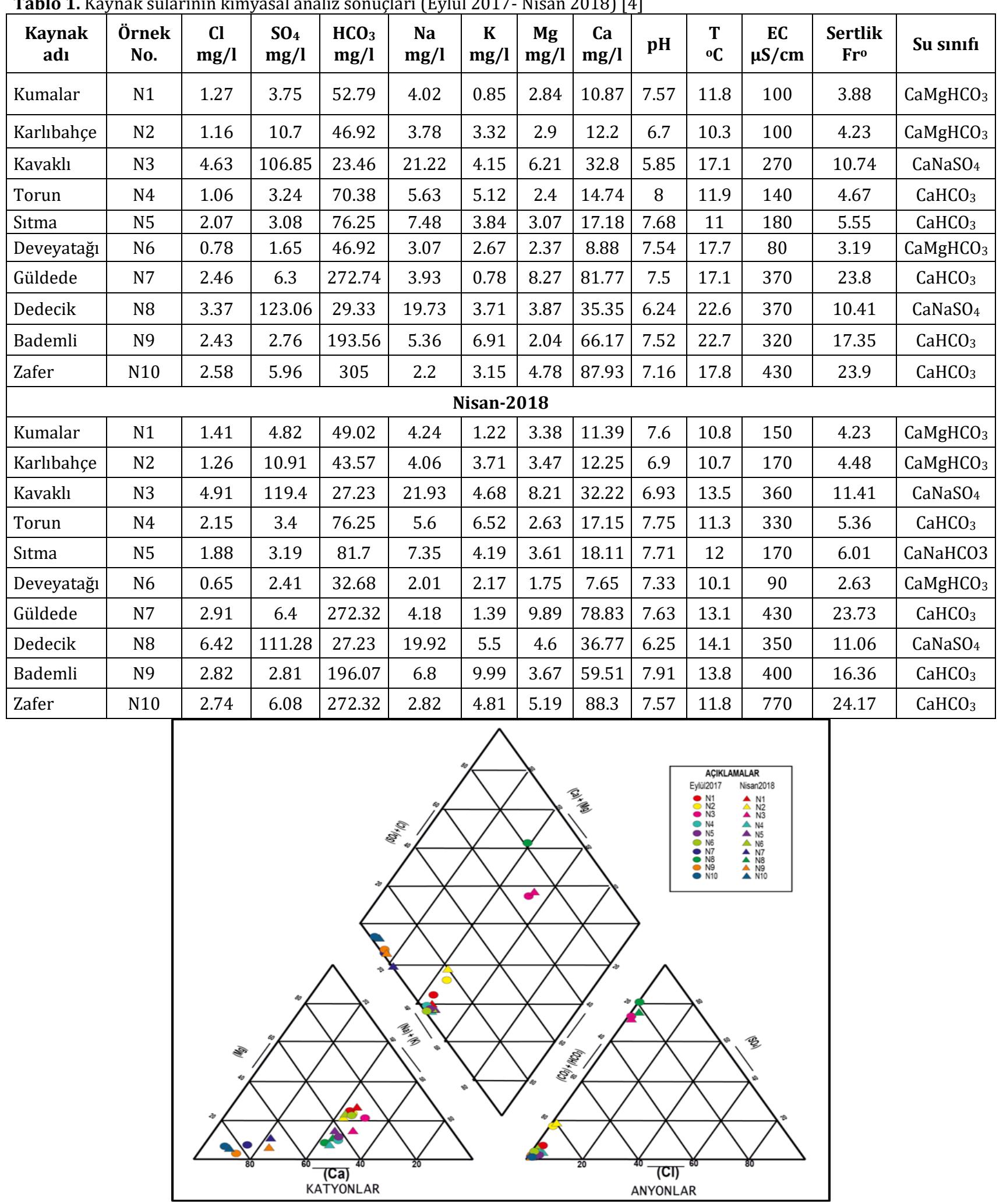

Şekil 4. Piper diyagramı [4] 
İnceleme alanında kaynak sularındaki farklı su tipleri etkileşimde olduğu kayaçlarla ilişkili olarak denetlenmektedir. Kayaçlarla temas süresi, suyun miktarı, sıcaklığı ve ortamın basıncı gibi faktörlere bağlı olarak yeraltısuyunun bileşiminde değişiklikler gerçekleşmektedir. İnceleme alanında $\mathrm{CaHCO}_{3}{ }^{\prime}$ lı sular sınıfında olan kaynakların beslendiği akifer, kireçtaşından oluşan Bakırdağ formasyonudur. Bu nedenle bu kaynaklarda $\mathrm{Ca}$ ve $\mathrm{HCO}_{3}$ iyonları baskındır. $\mathrm{Mg}$ artışı ise biyotit, hornblend, ojit ve piroksenin bozuşması ve dolomit-çört bantlı kireçtaşlarından oluşan Afyonluk formasyonu ile ilişkili olabilir.

$\mathrm{Na}$ ve $\mathrm{SO}_{4}$ içerikleri yüksek olan Dedecik ve Kavaklı kaynakları volkanit üyesini oluşturan dasit, riyolit, andezit vb. gibi yüksek alkali içeren kayaçlar ile ilişkili olarak boşalmaktadır. Na artışı volkanik kayaçlardaki albitlerin çözünmesi ve $\mathrm{Na}$ ile $\mathrm{Ca}$ arasında iyon değişiminin gerçekleşmesi ile açıklanabilir. $\mathrm{SO}_{4}$ artışı ise volkanik kökenli kayaçlar ve kırıntılı kireçtaşlarından oluşan Kumalar formasyonu içerisindeki piritlerin oksidasyonu ve Kumalar formasyonunun kömürlü seviyelerinin yıkanması ile açığa çıkmış olabilir. İnceleme alanında ayrışma yeraltısuyunda iyon konsantrasyonunu kontrol eden anahtar jeokimyasal proseslerden birisidir.

\subsection{Suların kullanım özellikleri}

Suların içilebilme özelliklerinin değerlendirilmesi için öncelikle suların kimyasal analiz sonuçları Türk İçme Suyu [6] ve Dünya Sağlık Örgütü [7] standartları ile karşılaştırılmıştır. İnceleme alanında kaynak sularından alınan örneklerin genel olarak fiziksel özellikleri ve anyon-katyon içeriklerinin sınır değerleri aşmadığı görülmektedir.

İnceleme alanındaki suların sulama amaçlı kullanılabilirliğinin değerlendirilmesinde Wilcox ve ABD Tuzluluk Laboratuvarı diyagramları ile Sodyum Adsorbsiyon Oranı (SAR), Artıksal sodyum karbonat (RSC), Geçirgenlik indeksi (PI) ve Magnezyum Tehlikesi (MT) değerleri kullanılmıştır.

ABD tuzluluk laboratuarı diyagrama göre Kumalar ve Karlıbahçe kaynak suları EC içeriklerinin düşük olması nedeniyle ' $C_{1} S_{1}$ ' (az tuzlu ve az sodyumlu sular), diğer kaynak suları ise ' $C_{2} S_{1}$ ' (orta tuzlulukta ve az sodyumlu sular) sınıflarındadır (Şekil 5). Wilcox [8] diyagramına göre İnceleme alanındaki sular, 'çok iyi kullanılabilir sular' sınıfında yer almıștır (Şekil 6).

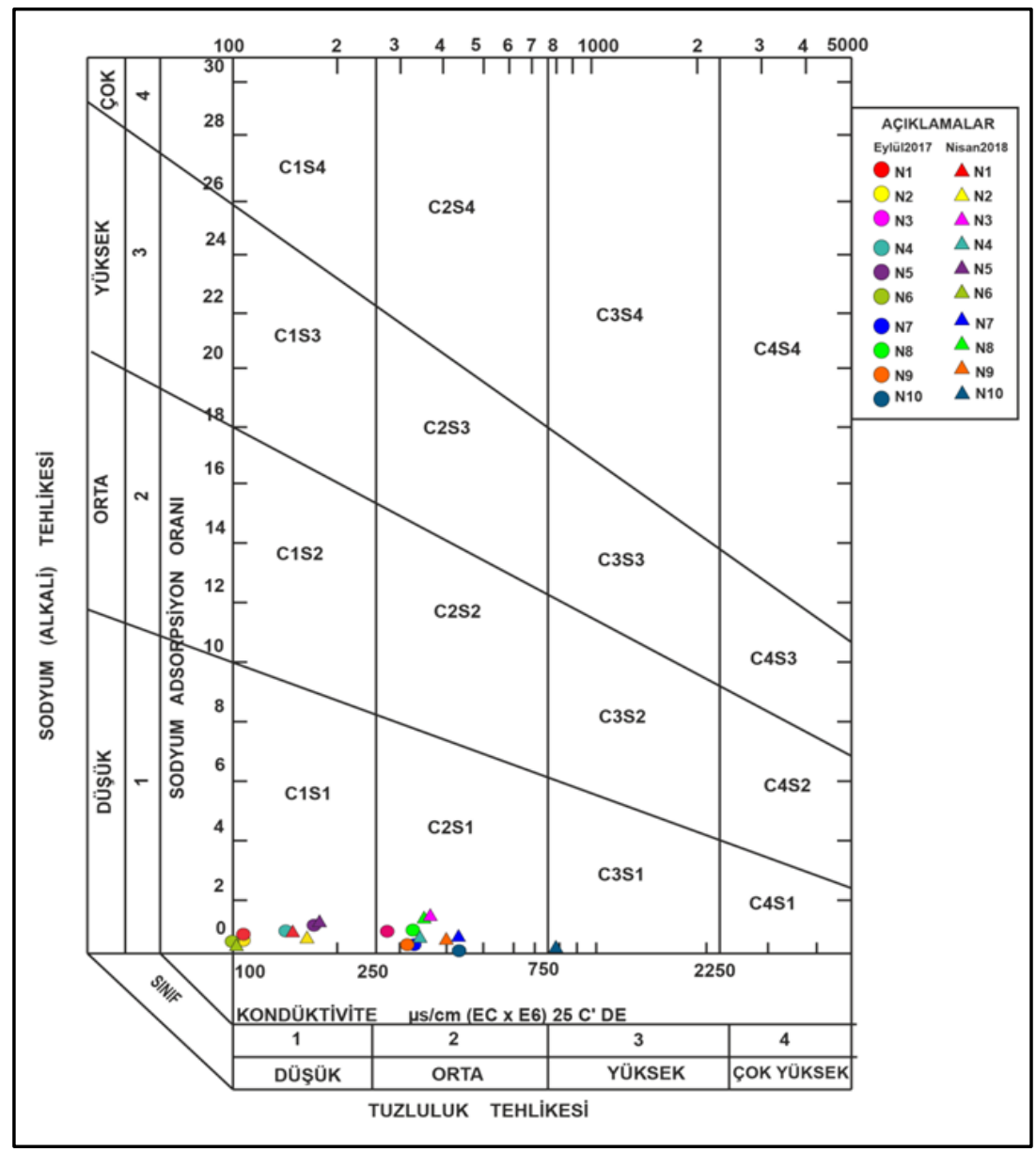

Şekil 5. ABD tuzluluk diyagramı [4] 


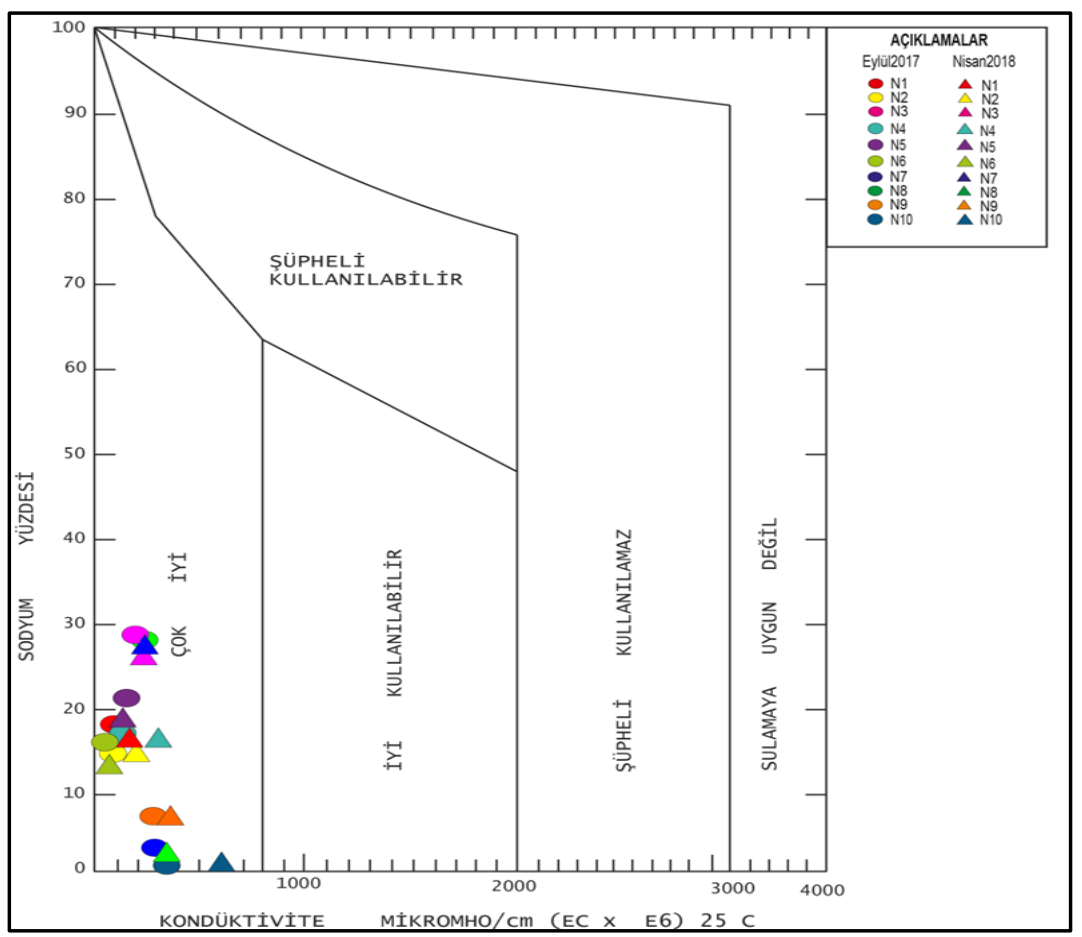

Şekil 6. Wilcox diyagramı [4]

İnceleme alanında bulunan kaynak sularının SAR değerleri Eylül-2017 döneminde 0.06-0.89, Nisan2018 döneminde 0.08-0.89 arasındadır (Tablo 2). Belirlenen SAR değerlerine göre sular 'Çok iyi özellikte sulama suyu' sınıfında yer almaktadır [4].

Suları RSC değeri <1.25 ise çok iyi (I. Sınıf su), 1.252.5 arasında ise iyi (II. Sınıf su), > 2.5 ise kullanılabilir (III. Sınıf su) olarak değerlendirilmektedir [9,10]. İnceleme alanına ait RSC değerlerine göre, Kavaklı ve Dedecik kaynak suları 'iyi' kaliteye sahip II. Sınıf su iken, diğer kaynak suları 'çok iyi' kaliteye sahip I. Sınıf sulardır.

İnceleme alanında Kumalar, Karlıbahçe, Torun, Sıtma ve Deveyatağı kaynaklarının PI değerleri <\%75 olup III. sınıf sulardır $[11,12]$. Diğer kaynak sularının PI değerleri ise \%25-75 arasında olup II. sinıf sulardır

MT $<50$ olan sular sulamaya elverişsli sulardır [13]. İnceleme alanında kaynak sularının MT değerleri \%4.84 ile 32.81 arasında değişmektedir (Tablo 2). Bütün su örnekleri MT değeri açısından sulama suyu olarak kullanıma elverişlidir.

\subsection{Suların kirlilik durumunun incelenmesi}

İnceleme alanında su kaynaklarında kirlilik parametrelerinin tespiti için Eylül-2017 ve Nisan2018 dönemlerinde ağır metal ve azot türevleri analizleri yapılmıştır (Tablo 3). İnceleme alanında kaynak sularının nitrat içerikleri 0.01-21.84 mg/l arasında değişmektedir. Nitrit ve amonyum içerikleri ise $<0.01 \mathrm{mg} / \mathrm{l}$ 'dir (Tablo 3). Nitrit, nitrat ve amonyum içerikleri açısından kaynak suları içme suyu için verilen limit değerleri aşmamaktadır.

Tablo 2. Suların sulama suyu olarak kullanım parametreleri

\begin{tabular}{|c|c|c|c|c|c|}
\hline $\begin{array}{c}\text { Kaynak } \\
\text { adı }\end{array}$ & $\% \mathrm{Na}$ & SAR & RSC & PI & MT \\
\hline \multicolumn{6}{|c|}{ Eylül-2017 } \\
\hline Kumalar & 17.96 & 0.28 & 0.09 & 116.21 & 30.09 \\
\hline Karlıbahçe & 15.02 & 0.25 & -0.08 & 102.93 & 28.12 \\
\hline Kavaklı & 29.06 & 0.89 & -1.76 & 50.25 & 23.79 \\
\hline Torun & 18.71 & 0.36 & 0.22 & 111.98 & 21.16 \\
\hline Sitma & 21.23 & 0.44 & 0.14 & 100.57 & 22.75 \\
\hline Deveyatağı & 15.89 & 0.24 & 0.13 & 130.98 & 30.54 \\
\hline Güldede & 3.46 & 0.11 & -0.29 & 46.34 & 14.29 \\
\hline Dede & 8 & 0.84 & 6 & 52 & 15.29 \\
\hline Bademli & 6.01 & 0.18 & -0.3 & 54.39 & 4.84 \\
\hline Zafer & 1.93 & 0.06 & 0.22 & 47.82 & 8.22 \\
\hline \multicolumn{6}{|c|}{ Nisan-2018 } \\
\hline Kumalar & 17.37 & 0.28 & -0.04 & 104.9 & 32.81 \\
\hline Karlıbahçe & 15.13 & 0.26 & -0.18 & 95.22 & 31.81 \\
\hline Kavaklı & 28.42 & 0.89 & -1.84 & 50.12 & 29.58 \\
\hline Torun & 16.45 & 0.33 & 0.18 & 103.53 & 20.16 \\
\hline Sitma & 19.64 & 0.41 & 0.14 & 97.12 & 24.74 \\
\hline Deveyatağı & 13.1 & 0.17 & 0.01 & 133.58 & 27.38 \\
\hline Güldede & 3.66 & 0.12 & -0.28 & 46.56 & 17.13 \\
\hline Dedecik & 26.91 & 0.82 & -1.77 & 49.84 & 17.09 \\
\hline Bademli & 7.74 & 0.23 & -0.06 & 58.55 & 9.23 \\
\hline Zafer & 2.42 & 0.08 & -0.37 & 45.11 & 8.83 \\
\hline
\end{tabular}


Tablo 3. Kaynak sularının ağır metal ve azot türevleri analiz sonuçları

\begin{tabular}{|c|c|c|c|c|c|c|c|c|c|c|c|c|c|}
\hline Kaynak Adı & $\begin{array}{c}\mathrm{Al} \\
\mu \mathrm{g} / \mathrm{l}\end{array}$ & $\begin{array}{c}\mathrm{As} \\
\mu \mathrm{g} / \mathrm{l}\end{array}$ & $\begin{array}{c}\text { B } \\
\mu \mathrm{g} / \mathrm{l}\end{array}$ & $\begin{array}{c}\mathrm{Cr} \\
\mu \mathrm{g} / \mathrm{l}\end{array}$ & $\begin{array}{c}\mathrm{Cu} \\
\mu \mathrm{g} / \mathrm{l}\end{array}$ & $\begin{array}{c}\mathrm{Fe} \\
\mu \mathrm{g} / \mathrm{l}\end{array}$ & $\begin{array}{c}\text { Mn } \\
\mu \mathrm{g} / \mathrm{l}\end{array}$ & $\begin{array}{c}\mathrm{Ni} \\
\mu \mathrm{g} / \mathrm{l}\end{array}$ & $\begin{array}{c}\mathrm{Pb} \\
\mu \mathrm{g} / \mathrm{l}\end{array}$ & $\begin{array}{c}\mathrm{Zn} \\
\mu \mathrm{g} / \mathrm{l}\end{array}$ & $\begin{array}{c}\mathrm{NO}_{2} \\
\mathrm{mg} / \mathrm{l}\end{array}$ & $\begin{array}{c}\mathrm{NO}_{3} \\
\mathrm{mg} / \mathrm{l}\end{array}$ & $\begin{array}{c}\mathrm{NH}_{4} \\
\mathrm{mg} / \mathrm{l}\end{array}$ \\
\hline & \multicolumn{13}{|c|}{ Eylül-2017 } \\
\hline Kumalar & 9 & 7.1 & 9 & 2.3 & 0.3 & $<10$ & 0.56 & $<0.2$ & $<0.2$ & 1.8 & $<0.01$ & 3.56 & $<0,01$ \\
\hline Karlıbahçe & 17 & 17.9 & 32 & 2.4 & 0.5 & $<10$ & 1.04 & 0.2 & $<0.2$ & 1.2 & $<0.01$ & 5.77 & $<0,01$ \\
\hline Kavaklı & 104 & 22.9 & 27 & 0.9 & 1.8 & $<10$ & 9.81 & 3.7 & $<0.2$ & 6.5 & $<0.01$ & 1.04 & $<0,01$ \\
\hline Torun & 10 & 10.2 & 13 & 1.3 & 0.4 & $<10$ & 0.68 & $<0.2$ & $<0.2$ & 1.4 & $<0.01$ & 1.64 & $<0,01$ \\
\hline Sitma & 6 & 11.8 & 20 & 1 & 0.4 & $<10$ & 0.63 & $<0.2$ & $<0.2$ & 1 & $<0.01$ & 3.12 & $<0,01$ \\
\hline Deveyatağı & 12 & 6.7 & $<5$ & 1.5 & 0.2 & $<10$ & 0.53 & $<0.2$ & $<0.2$ & 1 & $<0.01$ & 1.99 & $<0,01$ \\
\hline Güldede & 3 & 9 & $<5$ & 1.2 & 0.7 & $<10$ & 0.57 & $<0.2$ & $<0.2$ & 1.6 & $<0.01$ & 1.94 & $<0,01$ \\
\hline Dedecik & 68 & 18.6 & 38 & 0.6 & 0.8 & 3343 & 317.08 & 27.6 & $<0.2$ & 36.1 & $<0.01$ & 0.01 & $<0,01$ \\
\hline Bademli & 6 & 9.1 & 9 & 1.9 & 0.6 & $<10$ & 0.56 & $<0.2$ & $<0.2$ & 2.6 & $<0.01$ & 18.7 & $<0,01$ \\
\hline \multirow[t]{2}{*}{ Zafer } & 5 & 8.5 & 6 & 1 & 0.8 & $<10$ & 0.67 & $<0.2$ & $<0.2$ & 1.3 & $<0.01$ & 0 & $<0,01$ \\
\hline & \multicolumn{13}{|c|}{ Nisan-2018 } \\
\hline Kumalar & 11 & 8.3 & 9 & 2.5 & 0.4 & $<10$ & 0.67 & $<0.2$ & $<0.2$ & 54.7 & $<0.01$ & 4.12 & $<0,01$ \\
\hline Karlıbahçe & 13 & 14.1 & 25 & 2.2 & 0.4 & $<10$ & 0.54 & $<0.2$ & $<0.2$ & 40.4 & $<0.01$ & 6.02 & $<0,01$ \\
\hline Kavaklı & 97 & 20.7 & 22 & 0.9 & 1.7 & $<10$ & 12.23 & 3.0 & $<0.2$ & 42 & $<0.01$ & 1.21 & $<0,01$ \\
\hline Torun & 41 & 9.7 & 12 & 1.2 & 0.4 & $<10$ & 0.98 & $<0.2$ & $<0.2$ & 30.1 & $<0.01$ & 2.84 & $<0,01$ \\
\hline Sitma & 3 & 11.7 & 16 & 1.1 & 0.3 & $<10$ & 0.4 & $<0.2$ & $<0.2$ & 43.6 & $<0.01$ & 3.45 & $<0,01$ \\
\hline Deveyatağı & 15 & 6.1 & $<5$ & 1.1 & 0.2 & $<10$ & 0.44 & $<0.2$ & $<0.2$ & 12.4 & $<0.01$ & 1.96 & $<0,01$ \\
\hline Güldede & $<1$ & 13.7 & $<5$ & 1.6 & 0.5 & $<10$ & 0.25 & $<0.2$ & $<0.2$ & 16 & $<0.01$ & 2.45 & $<0,01$ \\
\hline Dedecik & 67 & 20.1 & 37 & 1.1 & 0.9 & 3261 & 357.24 & 25.3 & $<0.2$ & 50.2 & $<0.01$ & 0.05 & $<0,01$ \\
\hline Bademli & $<1$ & 12.1 & 9 & 2.1 & 0.5 & $<10$ & 0.45 & $<0.2$ & $<0.2$ & 6.2 & $<0.01$ & 21.84 & $<0,01$ \\
\hline Zafer & 14 & 9.2 & 7 & 1.1 & 0.5 & $<10$ & 2.05 & $<0.2$ & $<0.2$ & 19.3 & $<0.01$ & 1.92 & $<0,01$ \\
\hline TSE, 2005 & 200 & 10 & 1000 & 50 & 2000 & 200 & 50 & 20 & 10 & -- & 0.5 & 50 & 0.5 \\
\hline WHO 2011 & - & 10 & 2400 & 50 & 2000 & -- & -- & 70 & 10 & 5000 & 3 & 50 & - \\
\hline
\end{tabular}

$\mathrm{Bu}$ çalışmada, kaynak sularında $\mathrm{Al}, \mathrm{As}, \mathrm{B}, \mathrm{Cr}, \mathrm{Cu}, \mathrm{Fe}$, $\mathrm{Mn}, \mathrm{Ni}, \mathrm{Pb}$ ve $\mathrm{Zn}$ iyonlarının analizleri yaptırılmıștır. Kaynak sularının Al içerikleri <1-104 $\mu \mathrm{g} / \mathrm{l}$ arasında değiştiği görülmektedir (Tablo 3). Yeraltısularında Al varlığı volkanik kayaçlar içerisindeki kaolin, feldispat ve mika mineralleri ile ilişkili olarak kaya-su etkileşiminden kaynaklanabilmektedir [14].

İnceleme alanında kaynak sularının As değerleri 6.1$22.9 \mu \mathrm{g} / \mathrm{l}$ arasında değişmektedir (Tablo 3). İnceleme alanında Kumalar kaynağı ve Deveyatağ kaynağ dışındaki bütün kaynak sularının As içeriklerinin sınır değerleri aştığı yada sınır değere çok yakın olduğu görülmektedir. Arseniğin yeraltısularında bulunuşu bölgesel jeolojiye, hidrojeolojik özelliklere, akiferin jeokimyasal özelliklerine, iklim değişikliklerine ve insan faaliyetlerine bağlıdır. Doğal ortamda en yaygın arsenik kaynakları, volkanik kayalar (özellikle bazalt ve volkanik külün ayrışma ürünleri), denizel tortul kayaçlar, hidrotermal maden yatakları (ve jeotermal sular) ve fosil yakıtlardan gelmektedir.

İnceleme alanında kaynak çıkışlarının konumları ve beslenim-boşalım özellikleri dikkate alındığında As kirliliği olușturabilecek herhangi bir antropojenik etkinin olmadığı görülmektedir. Sularda As konsantrasyonunun artışı Göçen, Belceğez, Kocadere, Kumalar formasyonları ile Volkanit üyesi (bazalt, andezit, trakitten oluşan) birimlerindeki volkanik kökenli kayaçlar ile ilişkili olarak jeojenik kökenlidir.
Kaynak sularının, B <5-38 $\mu \mathrm{g} / \mathrm{l}$ arasında, Cr 0.6-2.5 $\mu \mathrm{g} / \mathrm{l}, \mathrm{Cu}$ 0,6-2,5 $\mu \mathrm{g} / \mathrm{l}, \mathrm{Zn}$ içerikleri 1.2-54.7 $\mu \mathrm{g} / \mathrm{l}$ arasında değișmekte ve $\mathrm{Pb}$ içerikleri $0.2 \mu \mathrm{g} / \mathrm{l}$ değerinin altında olduğu görülmektedir. Kaynak sularının Fe içerikleri <10-3343 $\mu \mathrm{g} / \mathrm{l}$ arasında, Mn içerikleri $0.25-357.24 \mu \mathrm{g} / \mathrm{l}$ arasında ve $\mathrm{Ni}$ içerikleri $<0.2-27.6 \mu \mathrm{g} / \mathrm{l}$ arasında değişmektedir.

Fe, Mn ve Ni elementlerindeki en yüksek değerler Kayabelen'de bulunan Dedecik kaynağında tespit edilmiş ve içme suyu sınır değerlerini aşmaktadır. Arazi çalışmaları sırasında Dedecik kaynağı civarında $\mathrm{Fe}, \mathrm{Mn}$ ve Ni artışına sebep olabilecek herhangi bir antropojen etken gözlenmemiștir. Bu kaynağın pH değerinin nisbeten düşük olması, sülfat içeriğinin yüksek olması ve $\mathrm{Fe}$, $\mathrm{Mn}$ ve $\mathrm{Ni}$ elementlerindeki artışlar burada asit kaya drenajının etkili olabileceğini göstermektedir. Asit kaya drenajı; başta pirit olmak üzere, sfalerit, galen, kalkopirit gibi sülfitli minerallerin hava ve su ile temasa geçerek oksidasyona uğraması ve sülfit mineralleri ile beslenen bazı bakteri türlerinin bu oksidasyon hızlarını arttırması ile oluşan doğal bir olaydır. Doğal ortamlarında yada insan faaliyetleri sonucunda bu kayaçların hava ve su teması ile yükselen asitlik değerleri nedeniyle asit kaya drenajı, artan çözünebilir metallerin ortama katılması sonucunda da yeraltısuyunun metal içerikleri artabilir [15]. Dedecik kaynağındaki Fe, Mn ve Ni artışları ile bu bölgedeki kaynak sularının büyük bir çoğunluğunda gözlenen As artışlarının asit-kaya drenajı ile ilişkili 
olarak kaya-su etkileşimden kaynaklandığg öngörülmektedir.

\subsection{Su kaynaklarının debi değişiklikleri}

Bu çalışmada inceleme alanı içerisinde farklı yerleşim yerlerinde bulunan 8 adet kaynak irdelenmiștir. Su kaynaklarının kullanımını sınırlayan önemli parametrelerden bir kaynak sularının miktarıdır.

Su kaynaklarının miktarını tespit etmek için Eylül2017 ve Eylül-2018 arasında aylık periyodik debi ölçümleri yapılmıştır (Tablo 4). İnceleme alanında su kaynaklarının debi değerleri Kumalar kaynağında 0.07-0.12 l/s, Karlıbahçe kaynağında 0.00-0.24 l/s, Kavaklı kaynağında 0.01-0.04 l/s, Torun kaynağında 1.30-3.0 l/s, Sitma kaynağında 0.42-0.55 l/s, Güldede kaynağında 0.12-0.47 l/s, Dedecik kaynağında 0.02$0.04 \mathrm{l} / \mathrm{s}$ ve Bademli kaynağında 0.05-0.18 l/s arasında değişmektedir [16].

Kaynaklarındaki debi değişimi iklimsel koşullara bağlı olarak yağışlı dönemde Aralık-Mayıs ayları arasında artış göstermektedir. Kaynakların tamamında mevsime bağlı dalgalanmalar görülmesine rağmen su yılının bașlangıcı olarak kabul edilen Eylül ayında 2017 ve 2018 yıllarında aynı debi değerleri ölçülmüştür. Bu durum beslenme koşullarının değişmediğini göstermektedir.

Kavaklı ve Dedecik kaynakları kömür içeren kırıntılılar ve kireçtaşından oluşan Kumalar formasyonu ve volkanit üyesini oluşturan dasit, riyolit, andezit gibi yüksek alkali içeren kayaçlar ile ilişkili olarak boşalmaktadır. Kavaklı kaynağının ortalama debisi $0.02 \mathrm{l} / \mathrm{s}$, Dedecik kaynağının ortalama debisi ise 0.03 l/s'dir. Kumalar, Karlıbahçe, TZM-1983 ve Oğuzhan Salih kaynakları, Kumalar formasyonuna ait, volkanik kökenli kayaçlar ile kırıntılı kireçtaşlarından boşalmaktadır [4, 16]. Kumalar ve Oğuzhan Salih kaynaklarının ortalama debileri 0.09 l/s'dir. TZM-1983 kaynağının ortalama debisi 0.18 , Karlıbahçe kaynağının ise $0.16 \mathrm{l} / \mathrm{s}$ olarak tespit edilmiştir.

Torun kaynağının ortalama debisi 1.81 l/s, Sitma kaynağının ortalama debisi $0.48 \mathrm{l} / \mathrm{s}$ ve Yıprak kaynağının ortalama debisi ise $0.01 \mathrm{l} / \mathrm{s}$ olarak tespit edilmiştir. Bu kaynaklar Kumalar formasyonuna ait volkanik kökenli kayaçlar ile kırıntılı kireçtaşları ve kireçtaşlarından oluşan Bakırdağ formasyonundan boşalmaktadır. Güldede kaynağı kumtaşı, kiltaşı, silttaşı, kireçtaşı ardalanmasından oluşan Kocadere formasyonundan boşalmaktadır. Kaynağın yıllık ortalama debisi $0.23 \mathrm{l} / \mathrm{s}$ 'dir. Bademli kaynağı ise olistolitli volkanik arakatkılı kumtaşı ve serpantinitten oluşan Göçen formasyonu ve alüvyon dokanağından boşalmaktadır. Kaynağın yıllık ortalama debisi $0.13 \mathrm{l} / \mathrm{s}$ olarak ölçülmüștür $[4,16]$.

İnceleme alanında su kaynakları için kaynak hidrografi analizi ile baz akım ve ortalama debi değerleri hesaplanmıştır. $\mathrm{Bu}$ hesaplamalara göre; kaynakların yıllık baz akım değerleri 311.04-4302.72 $\mathrm{m}^{3} /$ yll ve ortalama debi değerleri 0.01-1.81 l/s arasında değişmektedir $[4,16]$.

\section{Tartışma ve Sonuç}

Su kaynaklarının kullanım alanlarını kısıtlayan en önemli parametre suyun kimyasal yapısıdır. İnceleme alanındaki kaynak suları içme, kullanma, sulama ve hayvan yetiştiriciliğinde kullanılmaktadır. Kaynak sularının fiziksel özellikleri ve genel anyon-katyon içerikleri içme suyu standartlarına uygundur. Ayrıca, tarımsal faaliyetlerle ilişkili olarak yeraltısularında azot türevlerinin artışı suların içilebilirlik özelliğini kısıtlamaktadır.

Kaynak sularının nitrat, nitrit ve amonyak değerleri içme suyu sınır değerlerini aşmamaktadır. Kaynak sularının ağır metal içeriklerinde içme suyu olarak kullanım açısından en önemli problem As içeriklerinin yüksek olmasıdır. İnceleme alanında Kumalar kaynağı dışındaki bütün kaynak sularının As içeriklerinin sınır değerleri aştığı görülmektedir. Bu artışın kaynak sularının boşaldığı volkanik kökenli kayaçlarla ilişkili olarak kaya-su etkileşiminden kaynaklandığı düşünülmektedir. Benzer şekilde Kayabelen köyünde bulunan Dedecik kaynağında Fe, $\mathrm{Mn}$ ve $\mathrm{Ni}$ elementleri içmesuyu sınır değerlerinin üzerindedir.

Tablo 4. Kaynaklara ait aylık debi (l/s) ölçümleri (Eylül 2017-Eylül 2018)

\begin{tabular}{|l|c|c|c|c|c|c|c|c|}
\hline $\mathbf{2 0 1 7}$ & Kumalar & Karlıbahçe & Kavaklı & Torun & Sitma & Güldede & Dedecik & Bademli \\
\hline Eylül & 0.08 & 0.2 & 0.01 & 1.3 & 0.55 & 0.16 & 0.03 & 0.06 \\
\hline Ekim & 0.07 & 0.17 & 0.01 & 1.55 & 0.54 & 0.16 & 0.04 & 0.14 \\
\hline Kasım & 0.11 & 0.21 & 0.02 & 1.84 & 0.53 & 0.2 & 0.04 & 0.16 \\
\hline Aralık & 0.08 & 0.22 & 0.04 & 2.52 & 0.5 & 0.2 & 0.03 & 0.18 \\
\hline \multicolumn{7}{|c|}{$\mathbf{2 0 1 8}$} \\
\hline Ocak & 0.07 & 0.19 & 0.04 & & 0.51 & 0.21 & 0.02 & 0.14 \\
\hline Şubat & 0.09 & 0.2 & 0.02 & 3 & 0.49 & 0.16 & 0.02 & 0.14 \\
\hline Mart & 0.12 & 0.19 & 0.02 & 2.77 & 0.51 & 0.47 & 0.02 & 0.15 \\
\hline Nisan & 0.11 & 0.24 & 0.01 & 2.5 & 0.51 & 0.45 & 0.02 & 0.14 \\
\hline Mayıs & 0.09 & 0.22 & 0.01 & 2.22 & 0.48 & 0.29 & 0.02 & 0.06 \\
\hline Haziran & 0.12 & 0.21 & 0.01 & 1.99 & 0.46 & 0.35 & 0.03 & 0.17 \\
\hline Temmuz & 0.09 & 0.17 & 0.02 & 1.98 & 0.44 & 0.18 & 0.03 & 0.17 \\
\hline Ağustos & 0.08 & 0.07 & 0.03 & 1.96 & 0.43 & 0.15 & 0.03 & 0.16 \\
\hline Eylül & 0.08 & 0.08 & 0.03 & 1.85 & 0.42 & 0.12 & 0.03 & 0.05 \\
\hline
\end{tabular}


Kaynak sularının sulama suyu olarak kullanıma uygunluğu farklı grafik ve bağıntılarla irdelenmiştir. Elde edilen sonuçlar kaynak sularının sulama suyu olarak kullanıma uygun olduğunu göstermektedir.

Genel olarak su yönetimi açısından değerlendirdiğimizde su kaynaklarından miktar açısından küçük ölçekte faydalanılabileceği görülmektedir. Kumalar kaynağı inceleme alanında içmesuyu olarak kullanıma en uygun kaynaktır. Kaynak suyunun boşalım noktası oldukça yüksekte ve yerleșim yerlerine uzak mesafede olmasına rağmen bölge halkı içme sularını buradan karşılamaktadır. Kaynağın içmesuyu kalitesinde olması, kaynağın debisi ve boşalım koşulları dikkate alındığında, kaynak boşalım noktasının düzenlenmesi ve akışının kontrol altına alınarak faydalanma oranının artırılması gerekmektedir.

İnceleme alanında bulunan diğer kaynak suları içmesuyu olarak kullanıma uygun değildir. Yöre halkı bazı kaynakların içme suyu olarak kullanmamakta ancak, kullanma suyu ve hayvanların sulamasında kullanmaktadır. Kaynak sularının özellikle As içeriğinin yüksek olması hayvancılıkta ve evsel kullanımda uzun vadede sağlık sorunları oluşturabilecektir. İnceleme alanında kaynak sularının kimyasal içerikleri açısından sadece sulama suyu olarak kullanıma uygun olduğu görülmektedir. Ancak, debilerinin az olması nedeniyle küçük alanlarda sulama ihtiyacı için yararlanılabilirken büyük tarla sulamalarında kullanılamayacaktır.

\section{Teşekkür}

Yüksek lisans tezi kapsamında tamamlanan bu çalışma Süleyman Demirel Üniversitesi Bilimsel Araştırma Projeleri Yönetim Birimi 4888-YL1-17 No`lu proje ile desteklenmiştir. Ayrıca, Türkiye Bilimsel ve Teknolojik Araştırma Kurumu (TÜBİTAK3001; ÇAYDAG-116Y389) proje olanaklarından da yararlanılmıştır. Yazarlar çalışmayı destekleyen her iki kuruma da teşekkür ederler.

\section{Kaynakça}

[1] Balcl, V., 2011a. 1:100000 ölçekli jeoloji haritaları Afyon-L25 paftası. MTA Genel Müdürlüğü, Jeoloji Etütleri Daire Başkanlığı, Rapor No: 161, Ankara.

[2] Balcl, V., 2011b. 1:100000 ölçekli jeoloji haritaları Afyon-L24 paftası. MTA Genel Müdürlüğü, Jeoloji Etütleri Daire Başkanlı̆̆l, Rapor No: 162, Ankara.

[3] Öztürk, E.M., Öztürk, Z., 1989. BalçıkhisarKaraadilli (Afyon)-Dereköy (Isparta) Dolayının
Jeolojisi. MTA Genel Müdürlüğü, Derleme Rapor No.8946.

[4] Bal, Y., 2019. Şuhut (Afyonkarahisar) batısı su kaynaklarının hidrojeoloji ve hidrojeokimyasal incelemesi. SDÜ Fen Bilimleri Enstitüsü, Yüksek Lisans Tezi, 91s, Isparta

[5] Piper, A. M.,1944. A Graphic Procedure in the Geochemical Interpretation of Water Analyses. Trans. Amer. Geophys. Union, vol. 25, p. 914-923

[6] TSE-266, 2005. İnsani Tüketim Amaçlı Sular. Türk İçme Suyu Standartları TS 266 sayılı standart -Türk Standartları Enstitüsü -Ankara.

[7] WHO, 2011. Guidelines for Drinking-Water Quality, 4th Edt., World Health Organization, WHO Library Cataloguing-In-Publication Data, ISBN 9789241548151

[8] Wilcox, L.V. 1955. Classification and Use of Irrigation Waters, USDA Circular No. 969, P 19

[9] Eaton, F.M., 1950. Significance of Carbonate in Irrigation Water. Soil Sci, 69(2), 123-133

[10] Richards, L.A., 1954. Diagnosis and Improvement of Saline Alkaline Soils, US Department of Agriculture, HandBook 60 (160)

[11] Doneen, L.D., 1964. Water Quality for Agriculture. Department of Irrigation. University of Calfornia, Davis, 48.

[12] WHO, 1989. Health Guidelines for the Use of Wastewater in Agriculture and Aquaculture. In: Report of a WHO Scientific Group: Technical Report Series 778, WHO, Geneva, p 74

[13] Szabolcs, I., Darab, C., 1964. The Influence of Irrigation Water of High Sodium Carbonate Content on Soils. In I. Szabolics (Ed.), Proc 8th International Congress Soil Science Sodics Soils, Res Inst Soil Sci Agric Chem Hungarian Acad Sci, ISSS Trans II, 1964, 802-812.

[14] Eriksson, E., 1981. Aluminium in Groundwater Possible Solution Equilibria, Nordic Hydrology, 12, 43-50.

[15] Güneş, C., Tokgöz Güneș, S., 2011. Asit Drenajının Jeokimyasal Modellenmesi. 4. Madencilik ve Çevre Sempozyumu Bildiriler Kitabı. 2-3 Haziran 2011.

[16] Aksever, F., Davraz, A., Varol, S., 2019. Sandıklı ve Şuhut (Afyonkarahisar) Havzalarında Karstik Su Kaynaklarının Sürdürülebilir Kullanımı ve Su Yönetimi. Tübitak-3001, 116 Y389 nolu Proje Sonuç Raporu, 195s, Isparta 